\title{
Por uma pedagogia do equilíbrio
}

\author{
Kelley Cristine Gonçalves Dias Gasque \\ Universidade de Brasília \\ Ricardo Tescarolo \\ Pontifícia Universidade Católica/PR
}

\section{Resumo}

Neste artigo, discute-se a Pedagogia como a ciência prática que vincula as atividades de ensino e aprendizagem a uma sólida fundamentação científica, explicando e prescrevendo saberes e procedimentos de intervenção e desenvolvimento da Educação. Analisase de modo crítico uma visão fisicalista que reduz a Pedagogia a um programa de treinamento técnico sem objeto nem métodos próprios. É apresentada uma nova cosmovisão que reconhece 0 equilíbrio entre razão e experiência, considerando a importância da experiência na construção de novos conhecimentos, mediante o resgate da evolução histórica do conceito e o seu papel na aprendizagem e, conseqüentemente, na formação dos docentes. Ressalta-se igualmente que a consciência da experiência pode ser uma forma de tornar o ser humano responsável eticamente pelo ciclo de produção científica, pois as modificações ou transformações propiciadas pela ciência ocorrem em um mundo inseparável do ser no qual se insere a mente. Por isso, a discussão sobre experiência envolve, também, além dos aspectos cognitivos, a dimensão ética da ação humana. Nesse contexto, emerge a Pedagogia do Equilíbrio, que se constitui na simbiose das categorias complexas da totalidade, do movimento, da tensão e da superação na Educação. Conclui-se que a Pedagogia do Equilíbrio se funda não apenas na certeza de premissas e normas da reflexão racional ou da teorização científica, mas em seu equilíbrio com outros inúmeros fatores fundados em valores e princípios éticos que permitem ao ser humano empreender sua trajetória de conscientização e emancipação, visando a um mundo 'inédito mas viável', inspirado na utopia freiriana.

\section{Palavras - chave}

Pedagogia - Experiência - Ética - Equilíbrio.

\section{Correspondência:}

Kelley Cristine G. Dias Gasque

Cond. Mônaco DF140, K 2, Q.17, c.20

71680-601 - Brasília - DF

e-mail:

kelleycristinegasque@ hotmail.com 


\title{
For a pedagogy of balance
}

\author{
Kelley Cristine Gonçalves Dias Gasque \\ Universidade de Brasília \\ Ricardo Tescarolo \\ Pontifícia Universidade Católica/PR
}

\begin{abstract}
We discuss in this article Pedagogy as a practical science that links the teaching and learning activities to a solid scientific foundation explaining and prescribing knowledges and procedures for intervening in, and developing, education. We analyze in a critical way the physicalist view that reduces Pedagogy to a technical training program without its own object or methods. A novel worldview is presented which recognizes the balance between reason and experience, considering the importance of the latter in the construction of new knowledge, and recovering the historical evolution of the concept and its role in learning and, therefore, in teacher education. Likewise, we stress that the conscience of experience can be a way to make the human being ethically responsible for the cycle of scientific production, since the modifications or transformations brought about by science take place in a world inseparable from the being in which mind dwells. Thus, apart from cognitive aspects, the discussion about experience involves also the ethical dimension of human actions. In this context, there emerges a Pedagogy of Balance constituted by the symbiosis of the complex categories of totality, motion, tension, and overcoming in education. We conclude that the Pedagogy of Balance is founded not just on the certainty of premises and rules of rational reasoning or scientific theorizing, but on an equilibrium of numerous other factors based on ethical values and principles that allow the human being to walk his or her path of conscience and emancipation towards a world 'novel, but viable' inspired in the Freirian utopia.
\end{abstract}

\section{Ke yw ords}

Pedagogy - Experience - Ethics - Balance.

\footnotetext{
Contact:

Kelley Cristine G. Dias Gasque

Cond. Mônaco DF140, K 2, Q.17,

c. 20

71680-601 - Brasília - DF

e-mail:

kelleycristinegasque@hotmail.com
} 
0 pensamento ocidental sofre um processo de esgotamento e transição, resultado "da longa evolução a partir da consciência primordial indiferenciada através da alienação dualista" (Tarnas, 2003, p. 461), que se manifesta como uma epistemologia mais participativa e propicia a religação das individualidades humanas com a instância universal da existência.

Essa matriz conceitual emerge como um iceberg, cuja ponta visível é a veloz e profusa disseminação de informações, tendo a ciência e a tecnologia como fatores produtivos mais importantes. Parece assim se confirmar, como suposto por Gasque e Costa (2003), que as transformações técnico-científicas, econômicas, políticas e sociais impõem aos professores a necessidade de capacitação permanente para que possam assimilar inovações tecnológicas, novas formas de organização de trabalho e modos inéditos de produção. Em tal perspectiva, o ofício do professor se altera para contemplar um mundo em rápidas e constantes mudanças, no qual a formação continuada docente passa a ser uma das condições essenciais para a melhoria do processo de ensino e aprendizagem. Como decorrência, o profissional da Educação tem se questionado sobre o sentido da ciência pedagógica e o lugar que pode e deve ocupar nesses tempos de superação da

[...] lógica da razão que se configurou na modernidade, se independentizou e tomou rumos que nem sempre correspondem ao verdadeiramente humano. (Dias Sobrinho, 2005, p. 15)

De fato, segundo certa percepção que se tornou estigma entre muitos profissionais de outras disciplinas - senão entre os próprios pedagogos -, a Pedagogia não passaria de um programa mais ou menos sistemático de treinamento de técnicas de instrução, com prescrições de tarefas e adestramento de habilidades sem um conteúdo científico próprio.

Contra essa visão que consideramos equivocada, afirmamos que a Pedagogia constitui um saber científico legítimo, autônomo e unitário, produtor de saberes específicos elaborados por pensadores como Sócrates, Aristóteles, Comenius, Pestallozzi, Dewey, Freinet, Fröebel, Makarenko, Paulo Freire e entre muitos outros, sendo detentora de campo conceitual e metodológico próprio que não se submete aos esquemas formais da Física.

A concepção fisicalista ignora a natureza científica de boa parte das teorias, como a Pedagogia, cujas generalizações não se aplicam ao método da falseabilidade (Mayr, 2005). Ora, 'Ciências Duras' (Wissenschaften) não podem constituir padrão absoluto tanto para as Ciências Naturais quanto para as denominadas ' $\mathrm{Ci}$ ências do Espírito' (Geisteswissenschaften) ou, como adotamos mais freqüentemente entre nós em decorrência da tradição anglófona, as 'Ciências Humanas'. Para essa perspectiva, o termo ciência "é empregado em sentido enganadoramente inclusivo" (afinal, nem toda a opinião, arte ou técnica, ainda que sistematizada e elaborada, pode ser definida como ciência), como é equivocada "a decisão de alguns físicos e filósofos fisicalistas de restringir a palavra ciência à física fundada na matemática" (Mayr, 2005, p. 27-28).

A Pedagogia, ao explicar e prescrever conhecimentos e procedimentos de intervenção e desenvolvimento da Educação, supera essa visão preconceituosa e reducionista, que considera teoria científica apenas a que apresenta "um modelo matemático que descreve e codifica as observações que fazemos" (Hawking, 2001, p. 21).

Contra o anacronismo dessa cosmovisão, a Pedagogia deve propor o equilíbrio complexo e dialético entre reflexão e experiência e entre técnica e ética, para alcançar a integração das "dimensões especulativas e empíricas" e os princípios e conceitos "primordiais da tradição pedagógica" com o

[...] conjunto dos métodos, processos e procedimentos pelos quais se ensina e se aprende na complexidade do contexto real da sala de aula comum. (Gauthier, 1998, p. 332) 
Pedagogia: opinião, ciência ou técnica?

A Pedagogia é a ciência da qual os profissionais da Educação devem- se valer para elaborar a reflexão sobre a sua ação que, por sua vez, constitui a própria ciência pedagógica. 0 pensamento crítico sobre a prática educativa elabora a teoria que a organiza e a inspira, equilibrando a experiência social com a instância ideal de teorização. No entanto, embora "o processo de reflexão, tanto individual como coletivo, [seja] a base para a sistematização de princípios norteadores de possíveis ações, e nunca de modelos" (Pimenta; Anastasiou, 2005, p. 199), ele não se orienta por uma visão reduzida ou simplista de realidade,

[...] até porque as relações que a definem perdem-se porque não é possível analisá-la ou categorizá-la como pretende uma perspectiva mais ortodoxa. Além disso, tudo o que é relevante para a ação e o pensamento humanos tem implicações éticas e políticas, condição que não pode ficar excluída em uma análise desse tipo. (Tescarolo, 2004, p. 15)

Corroborando Suchodolski (apud Libâneo, 2004), entendemos a Pedagogia como "uma ciência sobre a realidade transformadora da realidade educativa", mediante a qual é possível desenvolver

\section{[...] uma nova determinação dos objetivos} da educação e de suas características fundamentais. [...] Numa época tão mutável como a nossa, os objetivos da educação devem decifrar-se nas perspectivas do futuro para 0 qual temos de preparar indivíduos. (p. 199)

A Pedagogia, como "ciência da educação em geral", apresenta "os fundamentos e fins da educação, o sujeito da educação, o educador e todos os tipos e modalidades de educação" (Quintanas Cabanas apud Libâneo, 2007 , p. 4). Ela tem, contudo, um sentido muito mais amplo, sendo "um campo de conheci- mentos sobre a problemática educativa na sua totalidade e historicidade e, ao mesmo tempo, uma diretriz orientadora da ação educativa", expressando assim finalidades sociopolíticas (Libâneo, 2004, p. 30-31).

A Ciência Pedagógica realiza-se no âmbito das práticas sociais, analisando-as, descrevendo-as, explicando-as, orientando-as e condicionando-as, bem como prescrevendo normas potencialmente eficazes, ao mesmo tempo em que participa delas. Elas se tornam, assim, parâmetros fundamentais da verdade teórica que as refletem, constituindo-se na práxis,

\section{[...] órgão de representação e instrumento de orientação do processo social global de afirmação humana da vida na natureza e na história que a teoria precisa refletir em suas leis objetivas, com cuja utilização consciente o homem pode chegar a um planejamento e um domínio científicos das forças naturais e da convivência social. (Schmied-Kowarzik, 1983, p. 21)}

Por isso, reconhece-se que a relação entre teoria e prática é fundamental em Educação, sendo constatada na pesquisa "como compreensão teórica da prática e condução prática à práxis através da teoria" (Schmied-Kowarzik, 1983, p. 10).

Os objetivos assumidos e os processos educativos empreendidos pela ação pedagógica contribuem, desse modo, para a percepção dos fatores que participam no desenvolvimento da pessoa em sua dinâmica de contínua significação espaço-temporal e que acabam por renovar o sentido de seu próprio objeto de estudo - a Educação.

0 equilíbrio pedagógico encontra, assim, o seu sentido no compromisso de intervir em uma realidade complexa, contingente e inesperada, identificando-se com um tipo de pensamento que supera a tendência de tornar impessoal o conhecimento e de separar o fato do valor e a ciência da humanidade.

A Pedagogia nutre-se dos saberes docentes, destacando o envolvimento do conhe- 
cedor em todos os atos de compreensão e intervenção da realidade em que este se insere. Participa de uma cultura integrada que resulta do esforço contínuo de investigar a experiência, que funda a razão e por ela se guia. 0 docente, assim, "constrói uma boa parte de seu saber na ação" (Gauthier, 1998, p. 342). E ainda que a ação docente se realize iluminada pela razão da ciência pedagógica que os docentes elaboram - ou que elaboram por, com ou para eles -, o que eles sabem da existência e do mundo, "mesmo por ciência", sabem-no a partir de sua própria experiência cotidiana,

\section{[...] sem a qual os símbolos da ciência não} poderiam dizer nada. Todo o universo da ciência é construído sobre o mundo vivido, e se queremos pensar a própria ciência com rigor, apreciar exatamente seu sentido e seu alcance, precisamos primeiramente despertar essa experiência do mundo da qual ela é a expressão segunda. A ciência não tem e não terá jamais o mesmo sentido de ser que o mundo percebido, pela simples razão de que ela é uma determinação ou uma explicação dele. (Merleau-Ponty, 1998, p. 3)

A experiência docente, integrada e subsidiada pela razão científica da Pedagogia, permite uma análise reflexiva que elabora "a síntese universal", isto é, o equilíbrio, superando a tendência do pensamento humano de absorver algumas idéias e experiências e de negar outras, colocando-as em oposições extremadas e excludentes. Assim, quando somos forçados a reconhecer que não se pode agir em termos de polarizações, sustentamos, para nos justificar, o argumento de que isso está certo na teoria, mas na prática as circunstâncias compelem ao acordo (Dewey, 1979b).

\section{Razão e experiência}

Os conceitos de razão e experiência historicamente opõem-se na cultura ocidental. 0 primeiro, proposto pelos gregos, marca um salto qualitativo na história do pensamento ocidental ao romper com o mito (mythos), conhecimento derivado das narrativas inspiradas por deuses, histórias e crenças populares que continham a verdade por si mesmo e dispensava toda a prova. Ao contrário, o segundo, instituído na tentativa e erro, não era passível de produzir um conhecimento verdadeiro.

A oposição entre logos - ou episteme e opinião representou outro marco que destacava a importância da razão. A episteme era uma nova forma de racionalidade, própria da ciência e da filosofia, em que o discurso do sujeito conhecedor é pensado como separado do objeto epistemológico, do qual deveria se apropriar por meio do pensamento.

$\mathrm{Na}$ idade moderna, ocorre a cisão entre a filosofia e a ciência. Descartes, figura central do pensamento científico moderno, enfatizou que a primeira era meramente especulativa ou reflexiva, em oposição à científica decorrente do experimentalismo ou método matemático, ou seja, o domínio do sujeito versus o domínio da coisa, da medida, da precisão (Vasconcellos, 2003).

A visão cartesiana ainda parece ser hegemônica no pensamento ocidental e suas limitações são constatadas, por exemplo, quando ela preceitua a separação entre o corpo e o espírito, resultando na idéia de estabilidade entre duas 'coisas' que se opõem, como o movimento de um pião que gira sobre si mesmo sem sair do lugar, utilizando a metáfora de Foucault (2004). Esse enfoque está subjacente à metáfora da mente como o software e o cérebro como o hardware, em uma visão que separa a mente do resto do organismo e evita o meio ambiente físico e social, excluindo a evidência de que parte do habitat também é produto das ações anteriores do organismo (Damásio, 1996).

A redução cartesiana compromete as distinções qualitativas como experiência e razão, que igualmente participam da essência da realidade vital. No entanto, a experiência, por remeter ao conhecimento ativo - e aqui destacamos a natureza prática da Ciência Pedagógica - parece ter sido sempre relegada e 
rechaçada como forma 'menor' de conhecimento na civilização ocidental.

Assim, depois de séculos de pensamento racionalista, o movimento de retorno à experiência como forma de também obter conhecimento, por suas características e amplitude, refletiu sobre a filosofia, produzindo os empiristas e os racionalistas - seus opositores - e depois os pragmatistas - que buscavam reconciliar as posições dos dois primeiros mediante a reconstrução dos conceitos de experiência e razão (Teixeira, 1959) - e mais adiante os fenomenologistas.

Seja qual for o sentido que tomarmos de razão, contudo, entendemos que existe, além desse campo,

\section{[...] outro domínio, pelo menos tão vasto} quanto ele, ou talvez ainda mais vasto, onde a compreensão racional e a descrição dificilmente encontram algo que possam captar. [...] Não há linguagem que esteja à altura deste paradoxo. 0 que quer que se diga, palavra alguma abarcará o todo... (J ung, 2002, p. 305)

Ortega y Gasset (1973) explica-nos que o termo experiência possui, em sua formação, o radical latino per, derivado da palavra periculum perigo, que significa 'ensaio', 'tentativa', 'prova' e não somente adversidade. 0 perigo corresponde à dúvida, à incerteza, à insegurança quanto à tentativa ou escolha diante do improvável ou imprevisível dessas duas alternativas. Assim, para sair da dúvida, é preciso provar, testar, experimentar, até que se desenvolva a perícia. Portanto, é na relação de cada um de nós com nossa circunstância que se constrói a experiência.

Para Ortega y Gasset, em sua obra El tema de nuestro tiempo, "razão é só uma forma e função da vida", inaugurando uma visão 'raciovitalista' que anuncia a simbiose entre vida e razão. Essa mesma idéia já aparecera em sua primeira publicação (Meditações do Quixote, de 1914), em que comenta: "Como se a razão não fosse uma função vital e espontânea da mesma linhagem que o ver e o apalpar", referindo-se à experiência vital humana (apud Marías, 2004, p. 502). Nessa mesma linha de reflexão, Kujawski (1994) explica, adotando o raciovitalismo de Ortega y Gasset, que "pensamos com a vista e com o tato, enxergamos e apalpamos com 0 pensamento". Assim, razão e experiência "não se excluem; pelo contrário, andam mesclados entre si e se entendem à perfeição", até porque

\section{[...] viver é não ter mais remédio senão ra- ciocinar ante a inexorável circunstância. Pode-se viver sem raciocinar geometrica- mente, fisicamente, economicamente, poli- ticamente. Tudo isso é razão pura e a hu- manidade viveu de fato milênios sem ela. Mas não se pode prescindir da razão vital, isto é, a razão encarnada no fluxo, no ritmo e na urgência da vida. (p. 58-59)}

Apropriando-nos de uma metáfora bíblica do livro do Apocalipse, empregada por Pozo (2005), sugerimos que a razão precisa urgentemente se fazer carne e passar a habitar entre nós, proporcionando um conteúdo às representações humanas que torne possível modificar os modelos cognitivos do mundo, elaborando uma nova epistemologia que considera a "prodigiosa diversidade dos elementos, das relações, das interações ou das combinações" (p.10), sobre as quais repousam o funcionamento dos sistemas e pelo jogo da interdependência e da dinâmica próprias de uma realidade resiliente e dinâmica (Rosnay, 1975).

A experiência, segundo Dewey (apud Abbagnano, 2000), evidencia-se principalmente por nossa capacidade de aprender e contém três características: ela não se reduz à intuição, não se confundindo com a consciência; é o âmbito de todo projeto racional (daí a advertência de Dewey de que a razão assume sempre função construtiva na experiência); e não é 'apenas' conhecimento, ainda que o inclua, mas compreende tudo o que cada ser humano 'vivencia'.

Um equilíbrio dinâmico se manifesta, assim, na produção do conhecimento que, por 
sua vez, implica o enfrentamento de problemas e a sua superação por meio do pensamento reflexivo. 0 resultado do processo de indagação indica a provisoriedade epistêmica, cuja estabilidade é admitida até que surjam novas perspectivas.

Quando nos deparamos com um problema, inicialmente buscamos uma vivência análoga para nos orientar e facilitar o aprender. As experiências passadas constroem conhecimentos úteis dos quais se originam as idéias. Então, a Educação deve se organizar de forma a considerar o processo de viver dos indivíduos, pois quando os alunos estudam assuntos distantes de sua experiência, que não despertam curiosidade e estão além do poder de compreensão, tendem a se tornar intelectualmente irresponsáveis, não questionando a significação do que aprendem e para que serve. Em outras palavras, a experiência não é a lembrança de tudo o que nos ocorreu, mas o que vivenciamos de forma consciente. De igual modo, é possível afirmar que a experiência é o fio condutor que guiará para o aprendizado (Dewey, 1979a).

A experiência é entendida, desse modo, em um sentido mais amplo de interação ativa ou passiva do sujeito com o mundo. Com isso, a atividade em si não constitui experiência nem 0 conhecimento tem um fim em si mesmo, mas está dirigido para ela. As idéias que temos, portanto, são hipóteses de ação e funcionam como referências. Um exemplo é quando a criança coloca o dedo na chama. A experiência surge quando o movimento é associado à dor que sente e do entendimento que colocar o dedo no fogo provoca queimadura. A sua parte cognitiva refere-se à percepção das relações. Haveria, então, dois tipos de experiência: a de 'ensaio e erro' e aquela que chamamos de 'reflexiva'.

Além disso, toda experiência contém um componente de inferência, como "o processo de chegar a uma idéia do que está ausente na base do que está presente" (Dewey, 1979a, p. 100), que ocorre por intermédio da sugestão despertada pelo que é visto e lembrado e dependerá primeiramente da experiência pessoal e posteriormente da coletiva, uma vez que ela não se processa apenas dentro do corpo e da mente das pessoas, isto é, não se sucede no vácuo, mas em um contexto específico.

Destarte, a natureza humana, ainda segundo o referido autor, depende muito da Educação e, por conseguinte, da Pedagogia. A humanidade elaborou ao longo dos séculos uma cultura transmitida mais pela educação do que pela herança biológica, embora depois tenham sido reconhecidas as evidências de que o ser humano também é resultado de certo grau de programação genética e que deve superar 'estágios' que não podem ser omitidos nem abreviados, donde o equilíbrio entre 0 natural e o histórico na evolução humana.

É preciso reconhecer que, embora exista um conjunto invariante de características que nos condicionam, elas se integram na capacidade humana de aprender e superar qualquer condicionamento natural, o que nos torna capazes de escolha. Daí não concebermos a experiência divorciada da razão, pois é incompreensível uma experiência 'desterrada' (disworlded). Varela, Thompson e Rosch (2003), citando MerleauPonty, defendem a visão que reconhece um entre-deux, um 'caminho do meio' que corresponde ao equilíbrio que provê a inter-relação entre razão e experiência e compõe o fundamento da ciência pedagógica.

\section{Equilíbrio: o caminho do meio}

Equilíbrio pedagógico é, essencialmente, virtuosidade. Não nos referimos, aqui, a uma virtuosidade do tipo heróica, individual ou moral, mas à que se realiza como consciência, não só de si, mas do mundo. Afinal, como diz Foucault (2004):

[...] não se pode conhecer a si mesmo como convém senão sob a condição que se tenha sobre a natureza um ponto de vista, um conhecimento, um saber amplo e detalhado. [...] Conhecimento de si e conhecimento da natureza não estão, portanto, em posição de alternativa, mas absolutamente ligados. (p. 339) 
A virtude é o meio-termo que afirma a nossa própria humanidade ao possibilitar 0 poder de ser e agir humanamente, isto é, de agir bem, que é a sua própria essência, passível de aprendizagem. E como equilíbrio, ela ocorre no cruzamento do Animal laborans com - Homo faber - como hominização - e do Homo faber com gente - como humanização.

Concordando com as idéias de Hannah Arendt desenvolvidas ao longo da obra $A$ condição humana (2001), reconhecemos que nossas identidades são reveladas em um contexto impregnado de ação, discurso e poder que se apresenta como a rede de relações em que nos constituímos como humanos. Tal condição estabelece um novo início como a história singular de cada recém-chegado e afeta de maneira única a vida daqueles com quem se entra em contato, constituindo a revelação de que cada um de nós não é, afinal, autor nem produtor isolado da ação, pois um outro, também sujeito dessa história, tê-la-á iniciado antes. Desse modo, a ação humana, em razão da força e da flexibilidade de seus processos, provoca conseqüências imprevisíveis e irreversíveis que só podem ser superadas por poderes inusitados. 0 primeiro é o poder de perdoar, que reverte ações passadas, contradizendo a condição natural de irreversibilidade dos acontecimentos. 0 outro é o de prometer e cumprir promessas, garantia de continuidade nas relações humanas, o que contraria a imprevisibilidade dos eventos e supera a limitação das pessoas de só terem fé em si mesmas e de sempre desconfiarem dos outros.

As virtudes incorporam um fundamento ético nessa situação contemporânea de mudança crítica em que a educação escolar é colocada como protagonista. É nesse contexto de perplexidades, porque humano, que o equilíbrio virtuoso da Pedagogia alimenta uma sabedoria que se dedica à construção da reciprocidade $\mathrm{e}$ do respeito à alteridade e à diversidade, propiciando um vínculo orgânico entre as pessoas. E será o mistério da vida que instigará esse dom a serviço do outro, mais do que os conhecimentos que começam e terminam em indivídu-
OS. É ela que definirá os encontros humanos como horizontes e dará a direção a uma realidade que não existe sem a presença das pessoas, tanto quanto estas sem ela.

No entanto, a educação para as virtudes não se realiza apenas com discursos, intenções ou idéias, mas por meio de uma atuação capaz de elaborar sua própria significação, pois o sentido da vida nesse mundo é apoiado pelo julgamento da ação e suas conseqüências', que por sua vez depende da decisão que a pessoa toma quando age e julga as conseqüências de seus atos.

Não sem razão, aliás, reforça-se atualmente a importância e a urgência da Pedagogia do Equilíbrio, colocada no centro das transformações profundas que ocorrem na sociedade contemporânea. Mesmo porque não é mais possível permanecer alheio, por exemplo, à banalização da violência e suportar a indiferença frente à discrepância entre crimes hediondos contra a vida e a dignidade humanas.

A escalada de violência talvez seja o pior dos males na sociedade humana contemporânea, porque resulta da progressiva degradação do pensamento e da confusão da capacidade de julgamento. Isso nos faz questionar sobre a possibilidade de relacionar o pensamento com a ética, como condição de discernimento da ação humana e de suas conseqüências. A ética constitui o equilíbrio entre a vontade e a liberdade de agir além do interesse individual e imediato e do uso meramente pragmático e utilitário da razão prática.

No entanto, constata-se hoje em dia que

[...] a liberdade é geralmente considerada como a possibilidade de fazer o que se quer. Fazer o que se quer a partir da vontade do ego é a atitude menos livre. Ser progressivamente mais livre é ser sensível às condições e possibilidades genuínas de alguma situação presente, é ser capaz de agir de maneira aberta, não condicionada pelo apego e volições egoístas. Essa abertura e essa sensibilidade incluem não apenas a esfera imediata das percepções da 
própria pessoa: possibilitam-na também a estimar os outros e a desenvolver uma percepção compassiva das aflições alheias. (Varela; Thompson; Rosch, 2003, p. 132)

A vontade e o livre-arbítrio poderiam não passar de ilusão na medida em que não seríamos de fato livres, mas inexoravelmente submetidos ao determinismo histórico e incapazes de viver sem pensar que somos autônomos em nossa vontade. Nesse sentido, a vontade e o livre-arbítrio não passariam de uma espécie de liberdade ilusória. Como negar, entretanto, a nossa livre escolha diante da impossibilidade de se determinar o futuro sem comparar o que acontece com o que aconteceria se não tivesse ocorrido o que de fato aconteceu? Como resolver tal paradoxo? Afinal, o futuro é imprevisível, mas se constrói com as histórias pessoais que constituem a história do mundo que se projeta no futuro.

Por isso a ética deve assumir hoje, segundo Gasque e Tescarolo (2004), um sentido mais radical: não só como responsabilidade a priori pelo outro, mas também a posteriori em relação às implicações das nossas ações muitas vezes inconscientes e não intencionais, mas sempre produtoras de conseqüências, construtivas ou destrutivas -, e aqui nos referimos à escola, que funciona como sistema, mas em que as pessoas agem e são principalmente mistério. Falamos aqui de uma ética interpessoal que reconhece a dimensão sagrada da relação de cada pessoa com a outra, que pode representar uma interrogação, um desafio ou uma ameaça, mas também uma resposta, um perdão, uma presença ou uma promessa.

A ética traduz a origem primordial das virtudes e constitui o encontro do conhecimento e da consciência, a condição fundamental da liberdade e da solidariedade universais como utopia. Não fosse desse modo, o sentido ético de toda ação humana acabaria se diluindo na bruma da não intencionalidade, da determinação inevitável e do não protagonismo humano. Ela representa, portanto, a referência para o juízo crítico das ações das pessoas em sociedade ao tomar como princípio os valores humanos, capaz de condicionar e parcializar uma listagem moral que, tomando como princípio hábitos e costumes, limita-se a determinar o que é proibido ou permitido, certo ou errado, lícito ou ilícito, meramente determinando obrigações e responsabilidades.

Como núcleo catalisador da Pedagogia do Equilíbrio, a ética propiciará o diálogo de cada pessoa com a sua própria consciência e com as consciências das outras pessoas, despertando-as de uma eventual indiferença em relação à agressão, à vida e à dignidade do outro.

Será, então, na perspectiva da ação humana sustentada pelo fundamento ético, que deve ser considerada a história de todas as pessoas e o conhecimento que nos converte e se compromete com a felicidade do outro e a integralidade da natureza. Há um determinado tipo de conhecimento que é prisão e destruição, mas aqui falamos de outro, que é libertação e vida. Essa é a idéia fundamental que deve impregnar o sentido da Pedagogia do Equilíbrio: como harmonia da diversidade na unidade, um possível que ainda não é, mas pode vir a ser, porque é a associação de razão, experiência e ética, paixão e competência, docência e discência. Um equilíbrio ideal de phronèsis (sabedoria prudente, mas corajosa) com a justa serenidade (ataraxia). Virtuosa porque é 0 equilíbrio utópico da bondade e da felicidade não apenas como recompensas, mas virtudes em si mesmas.

Esse é o equilíbrio pedagógico possível e necessário na contingência da prática educativa, integrando antigas dualidades: certeza com dúvida; convicção com hesitação; verdade com crença; ciência com consciência; racionalidade com intuição; razão com sensibilidade, como totalidade em movimento em busca de transcendência, do que está além, antes e acima de nós.

Essa Pedagogia considera igualmente a tensão integradora, constituindo-se no que denominaremos 'consiliência' - tomando emprestado e modificando o sentido do conceito criado por Wilson (1999) -, como o processo de integração de todo o conhecimento huma- 
no, contestando, porém, a perspectiva desse autor em seu entendimento de que seria a biologia a sua promotora.

A consiliência resultaria de um processo que considera três momentos: 0 da 'evolução', a permanente possibilidade de progredir, de ser e estar melhor; o da 'totalidade', que emerge da complexidade sistêmica; e o do 'desenvolvimento', que nasce na contradição que transforma, elaborando novas sínteses. Por isso, propomos um equilíbrio pedagógico catalisador de outros fundamentos para a aquisição do conhecimento e base para 0 desenvolvimento de uma sabedoria prática imprescindível aos educadores, isto é, todos nós.

0 equilíbrio se constitui, enfim, da simbiose das categorias complexas da totalidade, do movimento, da tensão e da superação e 'consilia' (sic) a sapientia, como a razão que nos distingue dos animais, e a prudência, como o pensamento científico que preside as atitudes virtuosas, como nos ensina Platão em sua obra A República (1993).

Todavia, importa mencionar a urgente necessidade de superar um desequilíbrio que hoje representa um imenso risco, qual seja: uma cosmovisão exclusivamente antropocêntrica e inter-humana que separou a Noosfera - termo teilhardiano que corresponde à camada humana reflexiva da Terra, em vias de unificação física e união espiritual, que ele denominou 'unanimização' - da Biosfera - a camada viva não reflexiva que alimenta e sustenta a Noosfera que por sua vez depende de sua preservação, numa simbiose cheia de energia, mas complexa e delicada (Chardin, 2003).

0 desequilíbrio cosmológico se desvaneceu na penumbra de um atomismo que produziu a noção de pessoa como 'indivíduo' (no sentido de 'inseparável', 'indivisível', como 'átomo') e provocou a hegemonia de uma perspectiva distorcida da natureza e o colapso do equilíbrio da relação do ser humano com o universo natural (O'Sullivan, 2004). Essa concepção nos separou da natureza, provocando um desequilíbrio que nos aproxima da catástrofe.

Diante disso, é urgente que se resgate uma ética planetária empenhada no equilíbrio da 'realidade sagrada primordial' do universo (O'Sullivan, 2004), estabelecendo um novo contrato de solidariedade com a Terra, a vida e o outro que nega o relativismo moral e a privatização de valores, 'consiliando' (sic) reflexão com emoção, sensibilidade e intuição.

\section{Considerações fina is}

As discussões propostas nesse artigo sugerem a importância de uma visão conciliadora (consiliente) da realidade, visto que o sentido do mundo e das coisas surge das atividades permanentes de intercâmbio mútuo de uma mente existente em um corpo que vive em um ambiente. Nesse sentido, precisamos tornar o ser humano responsável eticamente pelo ciclo de produção científica em prol da sustentabilidade da vida no planeta e da própria emancipação, visto que as modificações propiciadas pela ciência ocorrem em um mundo inseparável do ser. Assim, devemos nos colocar contra essas oposições excludentes (como sintaxe alternativa), uma posição que garante o equilíbrio entre a ciência e a experiência humana.

Logo, "negar a efetividade de nossa própria experiência no estudo científico" das relações de aprendizagem humana é "transformar o estudo científico de nós mesmos em um estudo sem um objeto". Por outro lado, negar ou subestimar a razão científica é recusar a possibilidade de nossa própria compreensão. Em verdade, "a experiência e a compreensão científica são como duas pernas sem as quais não conseguimos caminhar" (Varela; Thompson; Rosch, 2003, p. 29-30).

E será a Pedagogia, "desde seu lugar hermenêutico e dialético-crítico", que propiciará 'unidade e coerência aos processos da educação, a um discurso processual comum' (Marques, 1996, p. 84), em que se relacionam as ciências empíricas, as bases racionais e os elementos cognitivo-instrumentais dessas relações.

A Pedagogia do Equilíbrio, não obstante, realiza-se especialmente na prática e ‘na razão do professor, razão que se faz ação que, por sua vez, significa transformação e construção". 
0 docente, inspirado pela ciência da educação, poderá assim deliberar, julgar e decidir "as ações a serem adotadas no seu processo educacional" (Gauthier et al., 1998, p. 394), desenvolvendo a 'sabedoria prática' (phronèsis) proposta por Aristóteles, que dotará o professor de "perspicácia e sagacidade, antecipação e senso de oportunidade", presentes "no devir e na ação" e atuando permanentemente no território do prolífico e do multirreferencial, "do dúbio e do equívoco", de modo a permitir que o professor se adapte "à simultaneidade e à imprevisibilidade das situações" (p. 361-362), tão freqüentes no enfrentamento educacional cotidiano.

A Pedagogia do Equilíbrio funda-se não apenas na certeza de premissas e normas da re- flexão racional e da teorização científica, mas igualmente integrando outros inúmeros fatores culturais, neurocognitivos e bioaf etivos, sustentados por valores e princípios em nome dos quais o ser humano empreende sua trajetória ética de discernimento, visando a um mundo 'inédito, mas viável', inspirado na utopia freiriana (Freire, 1972).

Essa utopia revela-se como esperança essencial nesses tempos críticos, na medida em que "o ser real da pessoa é elã permanente de superação dela por ela mesma" () aspers apud Hannoun, 1998, p. 171), sempre havendo algo acima ou adiante dela que teleologicamente a atrai e assegura-Ihe a ética que permite refletir (teorizar) sobre sua experiência, sua razão e sua vontade em busca da emancipação.

\section{Referências bibliográfic as}

ARENDT, H. A condição humana. 10 ed. Tradução de Roberto Raposo. Posfácio de Celso Lafer. Rio de J aneiro: Forense Universitária, 2001.

ABBAGNANO, N. Dicionário de Filosofia. 4 ed. Tradução da 1 ạ edição brasileira coordenada e revista por Alfredo Bosi. Revisão da tradução e tradução dos novos textos Ivone Castilho Benedetti. São Paulo: Martins Fontes, 2000.

CHARDIN, T. de 0 fenômeno humano. [1955]. 6 ed. São Paulo: Cultrix, 2003.

DAMÁSIO, A. 0 erro de Descartes. São Paulo: Companhia das Letras, 1996.

DEWEY, J . Como pensamos: como se relaciona o pensamento reflexivo com o processo educativo - uma reexposição. Tradução e notas de Haydée Camargo Campos. 4 ed. São Paulo: Nacional, 1979a.

. Experiência e educação. São Paulo: Nacional, 1979b.

DIAS SOBRINHO, J. Dilemas da educação superior no mundo globalizado: sociedade do conhecimento ou economia do conhecimento? São Paulo: Casa do Psicólogo, 2005.

FOUCAULT, M. A hermenêutica do sujeito. Tradução de Márcio Alves da Fonseca e Salma Tannus Muchail. Edição estabelecida sob a direção de François Ewald e Alessandro Fontana. São Paulo: Martins Fontes, 2004.

FREIRE, P. Acción cultural y alfabetización de adultos. Seminário do professor Paulo Freire no Colégio Pio Latino, em Roma, de 20 a 22 de novembro de 1972.

GASQUE, K. C. G. D.; COSTA, S. M. de S. Comportamento dos professores da educação básica na busca da informação para formação continuada. Ciência da Informação, Brasília, v. 32, n. 3, p. 54-61, set./dez. 2003. Disponível em <http://www.ibict.br/ cionline/viewarticle. php? id=52\&layout=html>. Acesso em 11 dez. 2005.

GASQUE, K. C. G. D.; TESCAROLO, R. Sociedade da aprendizagem: informação, reflexão e ética. Ciência da Informação, Brasília, v. 33, n. 3, p. 35-40, 2004. Disponível em <http://www.ibict.br/cionline/viewarticle. php?id=631>. Acesso em 4 fev. 2006.

GAUTHIER, C. et. al. Por uma teoria da pedagogia: pesquisas contemporâneas sobre o saber docente. Tradução de Francisco Pereira de Lima. Ijuí: UNIJ UÍ, 1998. 
HANNOUN, H. Educação: certezas e apostas. São Paulo: UNESP, 1998.

HAWKING, S. 0 universo numa casca de noz. Tradução de Ivo Korytowski. São Paulo: Mandarim, 2001.

J UNG, C. Memórias, sonhos e reflexões. [1963]. Rio de J aneiro: Nova Fronteira, 2002.

KUJ AWSKI, G. de M. Ortega y gasset: a aventura da razão. São Paulo: Moderna, 1994.

LIBÂNEO, J. C. Pedagogia e pedagogos, para quê? 7 ed. São Paulo: Cortez, 2004.

Diretrizes curriculares da pedagogia. Disponível em <http://ced.ufsc.br/nova/Textos/>. Acesso em 09 set. 2007.

MARQUES, M. O. Pedagogia: a ciência do educador. 2 ed. ljuí: UNIJ UÍ, 1996.

MARÍAS, J . História da filosofia. Tradução de Claudia Berliner. São Paulo: Martins Fontes, 2004.

MAYR, E. Biologia, ciência única: reflexões sobre a autonomia de uma disciplina científica. Tradução de Marcelo Leite. São Paulo: Companhia das Letras, 2005.

MERLEAU-PONTY, M. Fenomenologia da percepção. São Paulo: Martins Fontes, 1998.

ORTEGA Y GASSET, J 0 homem e sua gente. Tradução de J osé Carlos Lisboa. Rio de J aneiro: Ibero-Americana, 1973.

O'SULLIVAN, E. Aprendizagem transformadora: uma visão educacional para o século XXI. São Paulo: Cortez; Instituto Paulo Freire, 2004.

PIMENTA, S.; ANASTASIOU, L. Docência no Ensino Superior. 2 ed. São Paulo: Cortez, 2005.

PLATÃO. A Repúlica. Tradução de Maria Helena Rocha Pereira. Lisboa: Fundação Calouste Gulbenkian, 1993.

POZO, J. I. Aquisição do conhecimento: quando a carne se faz verbo. Porto Alegre: Artmed, 2005.

ROSNAY, J. de Le macroscope: vers une vision globale. Paris: Editions du Seuil, 1975.

SCHMIED-KOWARZIK, W. Pedagogia dialética: de Aristóteles a Paulo Freire. São Paulo: Brasiliense, 1983.

TARNAS, R. A epopéia do pensamento ocidental: para compreender as idéias que moldaram nossa visão de mundo. Trad. Beatriz Sidou. 6 ed. Rio de J aneiro: Bertrand Brasil, 2003.

TEIXEIRA, A. Filosofia e educação. Revista Brasileira de Estudos Pedagógicos. Rio de J aneiro, v. 32, n. 75, jul./set. 1959. p. 14-27.

TESCAROLO, R. A escola como sistema complexo: a ação, o poder e o sagrado. São Paulo: Escrituras, 2004.

VARELA, J . F.; THOMPSON, E.; ROSCH, E. A mente incorporada: ciências cognitivas e experiência humana. Tradução de Maria Rita Secco-Hofmeister. Porto Alegre: Artmed, 2003.

VASCONCELLOS, M. J . E. Pensamento sistêmico: o novo paradigma da ciência. Campinas: Papirus, 2003.

WILSON, E. O. A unidade do conhecimento: consiliência. São Paulo: Campus, 1999.

Recebido em 07.06 .06

Aprovado em 31.10.07

Kelley Cristine Gonçalves Dias Gasque é doutora e mestre em Ciência da Informação pela Universidade de Brasília, especialista em Literatura Brasileira pela Universidade Católica de Brasília e graduada em Biblioteconomia e Documentação pela Universidade de Brasília.

Ricardo Tescarolo, doutor em Educação pela USP, mestre em Educação pela PUC-SP, licenciado em Letras e Pedagogia, é professor do programa de Pós-Graduação em Educação Stricto Sensu da PUC-PR. E-mail: rtescarolo@pucpr.br 